\title{
Glomerular Deposition of Properdin in Henoch-Schönlein Syndrome and Idiopathic Focal Nephritis
}

\author{
D. J. EVANS, D. GWYN WILliAMS, D. K. PETERS, J. G. P. SISSONS, J. M. BOULTON-JONES, \\ C. S. OGG, J. S. CAMERON, B. I. HOFFBRAND
}

British Medical fournal, 1973, 3, 326-328

\section{Summary}

Biopsy of renal tissue from four patients with idiopathic focal nephritis and three patients with HenochSchönlein syndrome showed that C3 and propendin were deposited with IgA in the glomerular mesangium, Clq could not be detected. These observations suggest that glomerular injury in disorders characterized by mesangial deposits of IgA and C3 is mediated via the properdin system.

\section{Introduction}

Focal glomerulonephritis is well recognized as an accompanimerit of various systemic diseases-such as bacterial endocarditis, systemic lupus erythematcsus, polyarteritis nodosa, Goodpasture's syndrome, and Henoch-Schönlein syndrome (Heptinstall, 1966)-but at least half the cases diagnosed on renal biopsy are not accompanied by systemic manifestations. This last group has long been recognized as presenting a distinctive clinical picture of recurrent episodes of haematuria accompanying upper respinatory tract infection (Volhand and Fahr, 1914; Baehr, 1926; Heptinstall and Joekes, 1959; Ross, 1960). In most of these patients glomerular disease does not progress to renal failure; the condition has therefore been termed benign recurrent haematuria (Ayoub and Vernier, 1965).

A major contribution to the immunopathology of this disorder was made when Berger (1969) found that a group of patients with this syndrome had deposits of $\operatorname{IgA}$ in the glomerular mesangium. Berger also found C3 deposits in a distribution similar to the IgA; IgG was often present, but in much smaller amounts as judged by the immunofluorescent appearances. Similar mesangial deposits of IgA and C3 (though usually with more pronounced fibrin deposition) have subsequently been reported in patients with HenochSchönlein syndrome (Berger et al., 1971).

The cause of $\mathrm{C} 3$ deposition in these syndromes has been puzzling, since IgA was known to be incapable of fixing complement via the classical pathway (involving $\mathrm{Cl}, \mathrm{C} 4$, and C2). Götze and Muller-Eberhard (1971) reported that aggregated IgA was capable of fixing $\mathrm{C} 3$ via the alternative path-

Royal Postgraduate Medical School, London W12 0HS

D. J. EVANS, M.B., Senior Lecturer in Pathology

D. GWYN WILLIAMS, M.R.C.P., Assistant Lecturer in Medicine

D. K. PETERS, M.R.C.P., Lecturer in Medicine and Immunolog

J. G. P. SISSONS, M.R.C.P., Registrar, Department of Medicine

J. M. BOULTON-JONES, M.R.C.P., Senior Registrar, Department of Medicine

Guy's Hospital, London SE1 9RT

C. S. OGG, M.D., M.R.C.P., Consultant Physician, Department of Medicine J. S. CAMERON, M.D., F.R.C.P., Senior Lecturer in Medicine and ConJ. S. CAMERON,
sultant Physician

Whittington Hospital, London N19

B. I. HOFFBRAND, D.M., M.R.C.P., Consultant Physician, Department of Medicine way. This raised the possibility that C3 deposition in the glomeruli of patients with mesangial $\operatorname{IgA}$ was the result of activation of this pathway. Though the precise reaction sequence of the alternative pathway remains incompletely clarified, activation of $\mathrm{C} 3$ in vitro is known to involve properdin and the glycine-rich $\beta$-glycoprotein (GBG or factor B of the properdin system) (Lachmann and Nicol, 1973). The purpose of this communication is to report the association of properdin and GBG with the mesangial deposits of $\mathrm{C} 3$ and IgA in idiopathic focal nephritis and Henoch-Sohönlein syndrome.

\section{Methods}

Renal biopsy specimens from seven patients were studied; all showed deposits of $\operatorname{IgA}$ in the mesangium. Four were obtained from patients with idiopathic focal nephritis presenting with haematuria and three from patients with HenochSchönlein syndrome.

\section{IMMUNOFLUORESCENT STUDIES}

Tissue was "snap-frozen" in liquid nitrogen and stored at $-70^{\circ} \mathrm{C}$. Three-micron cryostat sections were fixed in dry acetone at $4^{\circ} \mathrm{C}$ and washed in phosphate-buffered saline.

Sections were treated with fluorescein-conjugated antisera to IgG, IgA, IgM, C3, Clq, and GBG; propendin deposition was detected by an indireot technique using a 1:8 dilution of rabbit anti-human properdin antiserum and fluoresceinconjugated sheep anti-rabbit antibody. Antisera to IgG, IgA, and IgM were obtained from Wellcome Reagents Ltd., Beckenham, U.K. Antisera to Clq, C3, and GBG were provided by Professor P. J. Lachmann, and anti-propendin was a generous gift from Drs. McLean and Michael of the Department of Pediatrics, University of Minnesota, Minneapolis. All antisera were tested in an Ouchterlony plate and shown to be monospecific; in addition these reagents showed dissociation of positive and negative staining in studies of a large series of renal biopsies from patients with other types of glomerulonephritis.

\section{SERUM COMPLEMENT ASSAYS}

Serum was stored at $-70^{\circ} \mathrm{C}$; concentrations of $\mathrm{Clq}, \mathrm{C} 4, \mathrm{C} 3$, GBG, and properdin were estimated by radial immunodiffusion. Total haemolytic complement $\left(\mathrm{CH}_{50}\right)$ and the capacity of sera to generate convertase activity with cobra factor were measured as previously described (Lachmann et al., 1973; Williams et al., 1973). The haemolytic activity in fresh serum from three patients was tested before and after incubation for six hours at $0^{\circ} \mathrm{C}$.

\section{Results}

The immunofluorescent findings on the seven patients are shown in the table. An example of mesangial properdin is shown in the figure. 
Immunofluorescent Findings in Patients with Mesangial Deposits of IgA. (Fluorescent Appearances Graded on a Scale from 0 to +++ )

\begin{tabular}{|c|c|c|c|c|c|c|c|c|}
\hline Case No. & Diagnosis & Properdin & $\begin{array}{c}\text { Glycine-rich } \\
\beta \text {-glycoprotein }\end{array}$ & $\mathrm{Clq}$ & $\mathrm{C} 3$ & IgA & IgG & Fibrin \\
\hline $\begin{array}{l}1 \\
2 \\
3 \\
4 \\
5 \\
6 \\
7\end{array}$ & 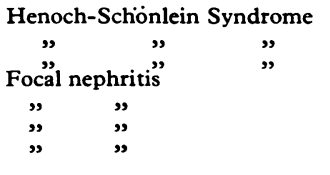 & $\begin{array}{l}+++ \\
++ \\
++ \\
++ \\
++ \\
++ \\
+\end{array}$ & $\begin{array}{l}- \\
\overline{+} \\
+ \\
\dot{+} \\
\dot{+} \\
+\end{array}$ & $\begin{array}{l}- \\
\overline{-} \\
\bar{z} \\
z\end{array}$ & $\begin{aligned} &-+ \\
&++ \\
&+ \\
&+ \\
&+ \\
&++ \\
&++ \\
&++\end{aligned}$ & $\begin{array}{l}+++ \\
+++ \\
+++ \\
+++ \\
+++ \\
+++ \\
+++\end{array}$ & $\begin{array}{r}+\bar{t} \\
+ \\
- \\
+ \\
+\overline{+}\end{array}$ & $\begin{array}{r}+ \\
++ \\
++ \\
+ \\
+ \\
+\end{array}$ \\
\hline
\end{tabular}

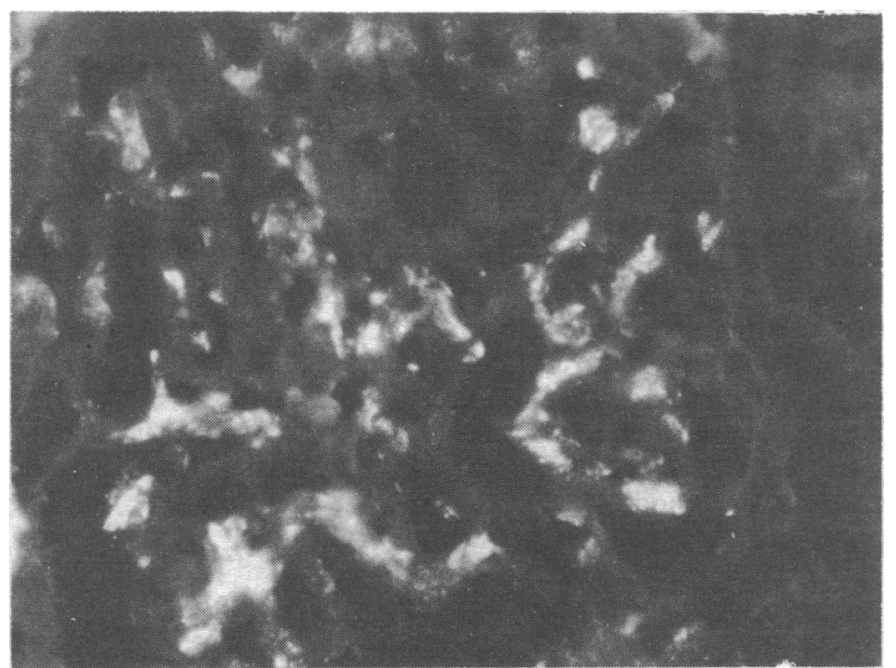

Example of mesangial properdin.

\section{COMPLEMENT STUDIES}

No abnormality was detected in the serum complement system. Total haemolytic complement and the serum concentrations of the components of the classical pathway (C1q and C4) and the alternate pathway proteins (GBG and properdin) were in the normal range. No significant loss of $\mathrm{CH}_{50}$ occurred in six hours at $0^{\circ} \mathrm{C}$.

\section{Discussion}

The finding of deposits of $\mathrm{C} 3$ and properdin in the absence of $\mathrm{Clq}$ provides good evidence that the $\mathrm{C} 3$ in the mesangium of these patients results from activation of the alternative pathway (the "properdin pathway"). It seems likely that this is due to deposition of $\operatorname{IgA}$, since C3 and IgA were found in all patients, whereas IgG was undetectable in some. Sussman et al. (1973) reported a patient totally deficient in C2, with the cutaneous manifestations of Henoch-Schönlein syndrome, indicating that the skin lesions can be independent of the classical pathway of complement activation. Our failure to deteot glycine-rich $\beta$-glycopnotein (GBG or properdin factor $B$ ) in the glomeruli of some patients showing properdin and C3 deposition suggests that this protein may be released from the site of complement activation. Direct evidence in favour of this interpretation has been obtained from in vitro studies of complement activation by zymosan (Brade et al., 1973).

Properdin and C3 have also been found in the glomerular lesions of acute poststreptococcal glomerulonephritis, chronic mesangiocapillary glomerulonephritis (Westberg et al., 1971), and in a propontion of patients with systemic lupus erythematosus (Rothfield et al., 1972). These disorders are often associated with hypocomplementaemia, and both in acute poststreptococcal nephritis (Williams et al., 1972) and mesangiocapillary nephritis (Spitzer et al., 1969; Peters et al., 1972; Thompson, 1972) there may be a circulating factor capable of breaking down C3 in vitro. The factor in the serum of patients with mesangiocapillary nephritis (C3 nephritic factor) has been shown to activate C3 by a reaction involving components of the alternative pathway (Williams et al., 1973). Day and Good (1973) reported that the serum of a patient with focal nephritis caused C3 breakdown in vitro at $0^{\circ} \mathrm{C}$; this patient also had deposits of $\operatorname{IgA}$, properdin, and $\mathrm{C} 3$ in the mesangium. This phenomenon was not observed in our patients, nor was any other abnormality detected in a detailed examination of the serum complement system.

The precise cause of IgA deposits in the mesangium in these disorders remains uncertain. It seems likely, but it is not proved, that IgA is deposited as an immune-complex, though circulating immune-complexes have not been detected in these patients. In Henoch-Schönlein syndrome there is circumstantial evidence favouring an allergic aetiology: hypersensitivity to drugs and bacterial and viral infection (including vaccination and poliovirus inoculation) have been implicated clinically. In idiopathic focal glomerulonephritis there is a striking clinical association between upper respiratory infection and haematuria. This association and the presence of $\mathrm{IgA}$ as the predominant immunoglobulin in the glomerular lesions makes it tempting to speculate that immune-complexes result from infection with an organism such as a virus which affects a mucosal site (and therefore provokes an IgA response).

Another possibility is that glomerular disease results from localization of virus (or other antigenic material) in the glomerular mesangium. The subsequent antibody response (which in the case of a virus infection may be ineffective at eliminating the virus) could then cause an allergic reaction at this site. Recurrent infection, by causing a heightened antibody response could also cause recurrent episodes of glomerular injury manifested by haematuria. Experimental evidence supporting this suggestion has recently been presented by Mauer and his colleagues in Minneapolis (1973), who have shown that antigenic material deposited in the mesangium can react with circulating antibody and that the resultant allergic reaction causes acute mesangial injury.

Whatever is the correct explanation for deposition of $\operatorname{IgA}$ in the mesangium, our observations add these syndromes to the disorders where activation of the alternative pathway seems to be responsible for complement mediated glomerular injury.

The Wellcome Trust provided generous support.

We thank Miss Jane Fallows and Miss Glenda Watts for skilled technical help.

Requests for reprints should be addressed to: Dr. D. K. Peters, Royal Postgraduate Medical School, London W12 OHS.

\section{References}

Ayoub, E. M., and Vernier, R. L. (1965). American fournal of Diseases of Children, 109, 217.

Baehr, G. (1926). Fournal of the American Medical Association, 86, 1001.

Berger, J. (1969). Transplantation Proceedings, 1, 939.

Berger, J., Yameva, H., Hinglais, N. (1971). In Actualités Néphrologiques de l'Hopital Necker, p. 17. Paris, Flammarion.

Brade, V., Lee, G., Nicholson, A., and Mayer, M. (1973). Journal of Immunology. Abstracts of Fifth International Complement Workshop. To be published. 
Day, N. K., and Good, R. A. (1973). Fournal of Immunology. Abstracts of Fifth International Complement Workshop. To be published.

Götze, O., and Müller-Eberhard, H. J. (1971). Fournal of Experimental Medicine, 134, 905.

Heptinstall, R. H. (1966). Pathology of the Kidney, p. 315. London, Churchill. Heptinstall, R. H., and Joekes, A. M. (1959). Quarterly fournal of Medicine, $28,329$.

Lachmann, P. J., and Nicol, P. (1973). Lancet, 1, 465.

Lachmann, P. J., Hobart, M. J., and Aston, W. P. (1973). Handbook of Experimental Immunology, ed. D. M. Weir. In press.

Mauer, M. S., et al. (1973). Fournal of Experimental Medicine, 137, 553.

Peters, D. K., et al. (1972). Clinical and Experimental Immunology, 11, 311. Ross, J. H. (1960). Quarterly Fournal of Medicine, 29, 391.
Rothfield, N., Ross, H. A., and Minta, J. O. (1972). New England fournal of Medicine, 287, 681 .

Spitzer, R. E., et al. (1969). Science, 164, 436.

Sussman, M., Jones, J. H., Almeida, J. D., and Lachmann, P. J. (1973). To be published.

Thompson, R. A. (1972). Immunology, 22, 147.

Volhard, F., and Fahr, T. (1914). Die Brightsche Nierenkrankheit. Berlin, Springer.

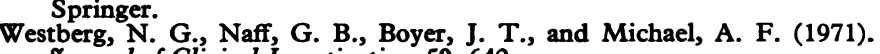
Fournal of Clinical Investigation, 50, 642.

Williams, D. G., Charlesworth, J., Lachmann, P. J., and Peters, D. K. (1973). Lancet, 1, 447.

Williams, D. G., Kourilsky, O., Morel-Maroger, L., and Peters, D. K. (1972). Lancet, 2, 360.

\section{PRELIMINARY COMMUNICATIONS}

\section{Induction Cardiac Pacing: A New Approach}

\author{
J. D. MCARTHUR, J. D. HENDERSON， M. M. MANI, \\ G. CHERIAN
}

British Medical fournal, 1973, 3, 328-329

\section{Summary}

A new approach to induction cardiac pacing using a "skin tunnel" transformer has been developed and used in a patient. Initial results are encouraging. If the system proves reliable in the long term it may have important applications in the delivery of power to implanted artificial organs.

\section{Introduction}

Permanent electrical pacing of the heart is firmly established as the treatment of choice in certain cardiac conditions, principally symptomatic complete heart block. Full utilization of this method of therapy in developing countries, however, has been impossible because of the very high cost of the permanent pacemaker.

In seeking a less expensive alternative we have devised and used a cheap permanent pacemaker using the induction principle. The problem, inherent in any induction-type pacemaker so far described, of maintenance of good approximation of primary and secondary coils has been overcome by using a "skin tunnel" transformer. Such a device has not been used previously in man and its successful utilization, reported here, may have important implications concerning the transfer of power from outside the body to implanted artificial organs.

\section{Principle of Method}

A diagram of the system is shown in fig. 1. The induction element is the skin tunnel transformer as described by Andren et al. (1968). In this technique an implanted coil is brought out

Christian Medical College Hospital, Vellore-4, South India

J. D. MCARTHUR, D.M., M.R.C.P., Reader in Cardiology
J. D. HENDERSON, B.SC., PH.D., Biomedical Engineer

M. M. MANI, M.S., AM.BD.CERT.PLAST.SURG., Head of Department of Plastic Surgery

G. CHERIAN, M.D., F.A.C.C., Professor and Head of Department of Cardiology in a tunnel of skin and thus can be coupled to the primary coil with a ring of ferrite material. By using a radio frequency impulse in our system the external coil has been reduced to one turn of stranded copper wire and the internal coil to three turns of insulated Elgiloy spring-coiled wire.* The latter is continuous at one end with the pacing electrode in the heart, and at the other with a stainless-steel capsule which acts as the indifferent electrode and also contains the only implanted electrical components, four diodes (only one is necessary but four are used for redundancy) to rectify the A.C. impulse.

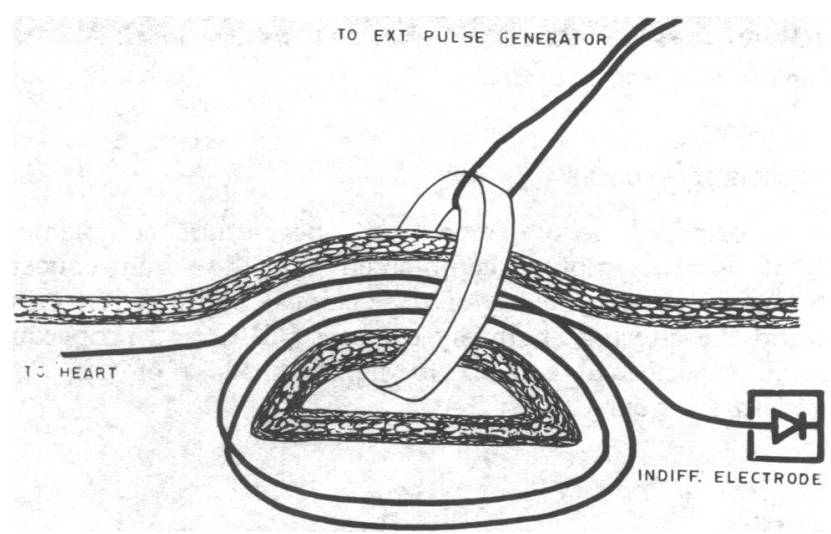

FIG. 1-Diagram of system using "skin tunnel" transformer.

\section{Clinical Trial and Results}

After successful animal experiments (McArthur et al., 1972 a; McArthur et al., 1972 b) the system was offered to a patient with complete heart block who could not afford a totally implanted system. An endocardial pacing lead was placed in the apex of the right ventricle using the saphenous vein approach (Sloman et al., 1970). Under general anaesthesia a skin tube was formed in the inguinal fossa region using standard plastic surgery techniques. Inside the tube were incorporated three loops of the insulated Elgiloy wire, the deep portions of the loops being placed under the external oblique muscle. The capsule was placed in the rectus sheath. When the tube had healed a ferroxcube toroid, $\dagger$ previously scored and broken in half, was reassembled round it and the loop of wire from the external unit passed through. (In fact, two loops were used for redundancy; see fig. 2.) The external generator, which will be described elsewhere, and which has two independent pacing circuits for safety, was worn in a leather case on a bett (fig. 3).

* Elgiloy Co., Elgin, Ill., U.S.A.

† Type 3E1, Philips Electron Devices, 116 Vandrehoof Avenue, Toronto 17, Ontario, Canada. 